\title{
De vernieuwde co-assistentschappen in Nijmegen: de eerste ervaringen
}

\author{
C.T. Postma, W.J.H.M. van den Bosch, R. Laan
}

\section{Samenvatting}

De vernieuwing van het curriculum is in het UMC St Radboud gevorderd tot in de klinische fase. De overgang is vloeiender geworden doordat in het praktisch klinisch onderwijs 2 (PKO-2) de klinische basisvaardigheden worden onderwezen. Het eerste klinische co-assistentschap - het co-assistentschap introductie kliniek - is sterk gestructureerd en tijdens dit co-assistentschap is er ook kleinschalig groepsonderwijs in het klinisch trainingscentrum. In het daaropvolgende co-assistentschap interne geneeskunde vinden uitgebreid zelfstandige contacten met patiënten plaats. Tussen de klinische co-assistentschappen zijn er centrale coassistentschappen in het klinisch trainingscentrum. Hierin is ruimte voor zowel reflectie op praktijkervaring in voorafgaande co-assistentschappen als voor voorbereiding op de volgende co-assistentschappen.

Tijdens de co-assistentschappen in het ziekenhuis wordt professioneel gedrag beoordeeld. De overige toetsing vindt plaats tijdens de centrale co-assistentschappen: een bespreking van een anamnesegesprek dat de student in de kliniek heeft gevoerd; stationsexamens voor de toetsing van vaardigheden betreffende het lichamelijk onderzoek en toetsing van klinisch redeneren in de vorm van patiëntenpresentaties en een klinisch pathologische conferentie.

Zowel studenten als docenten waarderen de vernieuwingen. Vooral de mogelijkheid om studenten feedback te geven op anamnesegesprekken scoort hoog. Ook de patiëntenpresentaties worden positief geëvalueerd. Anders dan verwacht, blijken studenten slechts in beperkte mate eigen initiatief te tonen bij de zelfstudie ter verdieping van kennis, opgedaan tijdens de klinische co-assistentschappen.

De gestructureerde mix van klinische en niet-klinische activiteiten met als kern de patiëntenzorg biedt de mogelijkheid voor de ontwikkeling van klinische ervaring en vaardigheden en een hierop gerichte verdieping van kennis. (Postma CT, Bosch WJHM van den, Laan R. De vernieuwde co-assistentschappen in Nijmegen: eerste ervaringen. Tijdschrift voor Medisch Onderwijs 2001;20(5):220-230.)

\section{Inleiding}

In november 1999 is de eerste groep van achttien studenten gestart met het eerste blok van de vernieuwde klinische fase van de opleiding geneeskunde. Enkele belangrijke kenmerken van het Nijmeegs curriculum zijn het tot stand brengen van een actief leerproces en een expliciete oriëntatie op de student. ${ }^{1}$ Het onderwijs is opgebouwd uit modules van vier weken. Het is disciplineoverstijgend met vanaf het eerste jaar een klinische oriëntatie. Het doel van de recente vernieuwingen was de veranderingen binnen het curriculum met een voor de klinische fase specifieke invulling te continueren. Daartoe werden de algemene doelstellingen voor de eerste fase nauwkeurig vastgelegd, waarna de leertrajecten werden uitgezet. ${ }^{2} 3$ Hier werd de verdere reconstructie op gebaseerd. Het modulaire systeem is in de klinische fase gehandhaafd met blokken en co-assistentschappen van vier of acht weken. Dit betekende een verkorting van 
een aantal co-assistentschappen, wat ook inhoudelijke consequenties had. Het proces van verandering, alleen al tengevolge van deze aanpassingen, was complex, niet alleen door de noodzakelijke aanpassingen zelf, maar ook door tegenwerpingen vanuit verschillende afdelingen.

Het principe van vooraf vastgelegde leerdoelen betekende voor de bestaande co-assistentschappen een herijking van veelal slechts impliciet bepaalde onderwijsdoelen, die algemeen bekend werden verondersteld. Dit laatste vormde waarschijnlijk ook de reden om daarover niet structureel van gedachten te wisselen.

De algemene en specifieke leerdoelen met de bijbehorende leertrajecten voor de blokken en de co-assistentschappen werden samen met een uitgebreide toelichting vastgelegd in blok- en stageboeken. ${ }^{4}$

Naast de herstructurering van de bestaande klinische stages werden nieuwe blokken en co-assistentschappen toegevoegd. Deze nieuwe elementen hebben met name betrekking op reflectie op de reeds gevolgde en voorbereiding op de nog komende co-assistentschappen. Binnen de nieuwe structuur zijn deze nu als expliciete en uitgewerkte programmaonderdelen opgenomen. Voorbereiding op de volgende co-assistentschappen vond binnen het vorige programma op bescheiden wijze plaats in de algemene co-assistentschappen. ${ }^{6}$

In het onderstaande wordt ingegaan op de blokken praktisch klinisch lijnonderwijs (PKO) 1 en 2, het co-assistentschap introductie kliniek en de centrale co-assistentschappen. PKO-1 is onderdeel van het derde jaar, PKO-2 en het aansluitende co-assistentschap introductie kliniek gaan direct vooraf aan de klinische stages. De centrale co-assistentschappen in het klinisch trainingscentrum zijn gepland tussen de klinische stages. Opzet en doelstellingen van het onderwijs worden beschre- ven en er wordt aandacht besteed aan de evaluatie van verschillende onderdelen van de vernieuwde co-assistentschappen.

\section{Voorbereiding en reflectie in de vernieuwde co-assistentschappen}

De voorbereiding is voor een deel gericht op de algemene aspecten van de klinische co-assistentschappen en kent daarnaast de meer disciplinegerichte voorbereiding. De belangrijkste elementen binnen de algemene aspecten zijn de arts-patiëntcommunicatie, het lichamelijk onderzoek en de interpretatie van de bevindingen, de kwaliteit van de medische probleemanalyse en het maken van beredeneerde afwegingen omtrent het te formuleren beleid. $\mathrm{Bij}$ dit laatste is het tevens belangrijk dat de studenten inzicht krijgen in het grote belang van een adequate communicatie daarover met alle betrokkenen. ${ }^{7}$

De algemene, disciplineoverstijgende voorbereiding vindt plaats tijdens de blokken praktisch klinisch onderwijs (PKO) 1 en 2. PKO-1 maakt deel uit van de blokken van het derde studiejaar. PKO-2 gaat direct vooraf aan de start van de in het ziekenhuis gesitueerde stages en wordt gevolgd door een co-assistentschap in de kliniek. Dit co-assistentschap introductie kliniek is een voorbereidingsperiode waarin de studenten kennismaken met de dagelijkse praktijk van de klinische geneeskunde.

Tussen de co-assistentschappen door zijn er drie centrale co-assistentschappen. Deze dienen enerzijds als voorbereiding op de aansluitende klinische co-assistentschappen en anderzijds als reflectie op de juist doorlopen co-assistentschappen. De disciplinespecifieke voorbereiding vindt plaats tijdens de centrale co-assistentschappen, direct voorafgaand aan de betreffende co-assistentschappen.

Het geheel van PKO-1 en 2, het co-assistentschap introductie kliniek en de cen- 
trale co-assistentschappen wordt de centrale klinische as genoemd met als sturend orgaan de Commissie Centrale Klinische As. Kenmerken van deze blokken zijn het disciplineoverstijgende karakter en de systematische opzet van het onderwijs. Daarnaast zijn ze, met uitzondering van het co-assistentschap introductie kliniek, ook fysiek geplaatst buiten de klinische afdelingen, in het klinisch trainingscentrum.

\section{De blokken Praktisch Klinisch Onderwijs 1 en 2}

Het blok PKO-1 maakt deel uit van het derde jaar. Centraal in het blok staat klinisch gericht onderwijs, bestaande uit zelfstudieopdrachten en praktische oefeningen in communicatietechnieken, lichamelijk onderzoek en klinisch probleemoplossen. Daarnaast is er plaats voor onderwijs en training in spoedeisende hulp, bedside teaching en andere vormen van klinische oriëntatie. Het geheel is een zo concreet mogelijke voorbereiding op de algemene vaardigheden vereist voor de directe patiëntenzorg. De hoofddoelstellingen van het blok kunnen worden omschreven als het op een zodanig niveau brengen van de klinische vaardigheden van de studenten dat ze deze in oefensituaties buiten de klinische setting op een beginnersniveau beheersen.

Het blok PKO-2 gaat direct vooraf aan het co-assistentschap introductie kliniek, het eerste co-assistentschap op een klinische afdeling. Het onderwijs in PKO-2 is erop gericht de studenten de anamnese en de fysische diagnostiek zodanig te leren dat ze deze in de klinische setting bij echte patiënten zelfstandig kunnen toepassen. Gespreksvoering is primair gericht op het anamnesegesprek. De fysische diagnostiek strekt zich ook uit tot de interpretatie van pathologische bevindingen bij het algemeen lichamelijk onderzoek. De principes van klinisch denken en handelen komen opnieuw aan de orde, waarbij de gebruikte casuïstiek een oplopende graad van moeilijkheid kent. Dit blok bouwt voort op het onderwijs in PKO-1. Dezelfde onderwerpen komen aan de orde, niet als herhaling, maar als uitbreiding. Niet alleen het aantal vaardigheden neemt toe, er worden ook ingewikkelder vaardigheden geleerd. Wat studenten reeds worden verondersteld te weten en kunnen vanuit PKO-1 wordt op een hoger niveau van beheersing gebracht. De hoofddoelstellingen van de training in dit blok zijn dat de studenten in het aansluitende co-assistentschap zelfstandig patiëntencontacten op een adequate wijze kunnen uitvoeren en een beredeneerd plan voor verder onderzoek of behandeling kunnen formuleren. ${ }^{4}$

\section{Het co-assistentschap introductie kliniek}

Het co-assistentschap introductie kliniek onderscheidt zich van de voorgaande onderwijsperioden doordat het plaatsvindt op de klinische afdelingen van het universitair medisch centrum. Daardoor wordt het leerproces in belangrijke mate bepaald door de eisen van de patiëntenzorg. Dit levert een van de belangrijkste leermomenten van dit co-assistentschap op. Immers de gehele gang van zaken op een klinische afdeling is voor de co-assistenten nieuw. Zij zijn wel eerder op afdelingen op bezoek geweest, maar nu leren ze van binnenuit de gang van zaken kennen. Dit gebeurt op een gestructureerde manier waarbij via de vastgelegde leertrajecten de leerdoelen dienen te worden bereikt. De kennismaking met de patiëntenzorg verloopt op indringende wijze doordat de studenten er direct bij betrokken zijn. De student voert zelfstandig de basale algemene vaardigheden van een arts uit, te weten communicatie met de 
patiënt en verrichten van het lichamelijk onderzoek.

Tijdens dit co-assistentschap zijn er vele momenten van reflectie ingebouwd, gericht op alle facetten van de patiëntenzorg. Deze vinden plaats in het klinisch trainingscentrum in een vaste groep van achttien studenten met een uitgebreide en gestructureerde begeleiding. De co-assistenten zijn geplaatst op afdelingen waar op dat moment geen andere co-assistenten disciplinespecifieke co-assistentschappen volgen. Dit voorkomt vermenging van taken en bevoegdheden en schept voor de verpleging en andere medewerkers op de afdelingen de nodige duidelijkheid.

Tijdens dit co-assistentschap doen de studenten hun eerste ervaringen op met zelfstandige contacten met patiënten. Gezien het beginnende karakter van deze contacten worden er expliciete eisen gesteld aan de begeleiding, die veel uitgebreider is dan voorheen tijdens de eerste co-assistentschappen gebruikelijk was. De begeleiding is sterk gestructureerd en vastgelegd in het stageboek.

\section{De centrale co-assistentschappen \\ 1 en 2}

De centrale co-assistentschappen vinden plaats in het klinisch trainingscentrum. Er is reflectie en verdieping betreffende de voorgaande co-assistentschappen en voorbereiding op de volgende co-assistentschappen. De reflectie in centraal coassistentschap 1 heeft betrekking op zowel het co-assistentschap introductie kliniek als het co-assistentschap interne geneeskunde. In de praktijk wordt met name teruggekeken op het co-assistentschap interne geneeskunde, omdat dit voor alle studenten hetzelfde is, terwijl de introductie kliniek op verschillende afdelingen plaatsvindt. In centraal co-assistentschap 2 wordt teruggeblikt op de co- assistentschappen neurologie, psychiatrie en kindergeneeskunde.

Alle studenten moeten een volledige ziektegeschiedenis presenteren van een patiënt die ze zelf hebben gezien. Uit deze presentaties worden door de studenten en de tutor onderwerpen gekozen die uitgediept moeten worden middels het raadplegen van studieboeken en recente literatuur met name ook via internetbronnen. Op deze manier wordt er naar aanleiding van reflectie verdieping bewerkstelligd van de kennis die de studenten tijdens het co-assistentschap hebben verworven.

Gedeeltelijk geschiedt de reflectie ook middels opdrachten waarvoor de co-assistenten tijdens het co-assistentschap in de kliniek gegevens moeten verzamelen afkomstig van de ziektegeschiedenissen van patiënten die ze zelf hebben gezien. Aan de hand van deze gegevens worden tijdens het centraal co-assistentschap specifieke onderwerpen behandeld.

De gegevens van de patiënten worden op deze manier bij drie gelegenheden steeds verder uitgediept. Er is een eerste bespreking met feedback op de klinische afdelingen, een tweede tijdens de patiëntenpresentaties in het centraal co-assistentschap en er is een derde bespreking tijdens de disciplinespecifieke werkgroepbesprekingen in het centraal co-assistentschap. Deze besprekingen zijn geen herhalingen, maar een steeds verder doordringen tot de kern van de klinische problematiek. De opdrachten voor het ene onderdeel zijn wat nauwkeuriger omschreven dan die voor het andere. Voor farmacologie zijn de opdrachten vrij specifiek, voor ethiek veel globaler. Om de studenten een zo groot mogelijke vrijheid te bieden om onderwerpen in te brengen die zij zelf belangrijk vinden, zijn de omschrijvingen voor ethiek zo gekozen dat iedere patiënt waarbij een ethisch probleem aan de orde komt, kan worden ingebracht. Hiermee 
wordt voorkomen dat de werkgroepbesprekingen een soort hoorcolleges worden met de studenten in een passieve rol. Alle onderwerpen worden zodoende aangedragen vanuit de ervaringen die de studenten zelf hebben gehad.

Naast reflectie en verdieping zijn er werkgroepen en practica als voorbereiding op de komende co-assistentschappen. Tijdens centraal co-assistentschap 1 zijn dit de co-assistentschappen neurologie, psychiatrie en kindergeneeskunde. Gezien de aard van deze co-assistentschappen betreft deze voorbereiding weinig actief oefenen van manuele en motorische vaardigheden, maar ligt de nadruk op het oefenen van cognitieve vaardigheden. De voorbereiding tijdens het centraal co-assistentschap 2 is gericht op heelkunde en gynaecologie en obstetrie. Dit betreft vooral sterk technisch-praktische vaardigheden, zoals de instructie van het gynaecologisch onderzoek door zelfstandig werkende docentes gynaecologisch onderzoek, een dag oefening in acute hulp, het leren wondhechten, chirurgisch wassen en het zwangeren-onderzoek.

Het meeste contactonderwijs wordt verzorgd door tutoren. Daarnaast zijn er docenten voor de specifieke, disciplinegerichte onderdelen. De tutoren in het centraal co-assistentschap 1 zijn overwegend stafleden van de afdeling interne geneeskunde, die eens per jaar een groep van negen co-assistenten begeleiden. In het centraal co-assistentschap 2 fungeert een groep huisartsen als vaste tutoren. $\mathrm{Zij}$ begeleiden om de maand een groep. Het totale cohort bestaat uit achttien studenten, die door twee tutoren en de overige docenten in groepen van negen worden begeleid. Een dergelijk cohort van achttien studenten trekt als groep door de gehele klinische fase. Om de vier weken start een nieuw cohort met PKO-2 en doorloopt achtereenvolgens de overige klinische stages.

\section{Beoordeling en toetsing in de centrale klinische as}

Na uitvoerige discussie werd besloten een belangrijk deel van de toetsing van de coassistentschappen uit te voeren tijdens de centrale co-assistentschappen. Dit betreft met name de toetsing van de praktische vaardigheden. Tijdens de co-assistentschappen vindt er een beoordeling plaats van de ontwikkeling van de co-assistent wat betreft het professionele functioneren. De co-assistentenopleider moet van oordeel zijn dat ter plaatse voldoende ontwikkeling is getoond om het co-assistentschap succesvol te kunnen afronden. Deze beoordeling wordt met de co-assistent besproken tijdens een beoordelingsgesprek halverwege het co-assistentschap en aan het eind van het co-assistentschap. Voor deze beoordelingen en de beoordelingsgesprekken zijn specifieke criteria ontwikkeld en op standaardformulieren vastgelegd. Dit bevordert dat de coassistentenopleiders een vast stramien aanhouden in de beoordelingen, terwijl er ook op de diverse afdelingen en ziekenhuizen eenzelfde beoordelingsprotocol wordt gevolgd. Er is tijdens de co-assistentschappen geen specifieke toetsing meer in de vorm van een examen.

De toetsing tijdens de centrale co-assistentschappen is gericht op het systematisch beoordelen van de vaardigheden die de studenten tijdens de co-assistentschappen hebben verworven op het gebied van de anamnese en communicatie, lichamelijk onderzoek en klinisch inzicht.

De anamnesevaardigheden worden beoordeeld aan de hand van een audio- of videoregistratie die de co-assistent tijdens het co-assistentschap interne geneeskunde heeft gemaakt van een anamnesegesprek met een poliklinische patiënt. De patiënt heeft hiervoor expliciet toestemming gegeven. Het gesprek duurt ongeveer een half uur. De co-assistent bekijkt 
de opname samen met de tutor. De tutor geeft feedback en tevens een beoordeling. Zowel studenten als docenten geven zeer gunstige evaluaties van dit onderdeel. De docenten zien het als een zeer waardevolle aanwinst dat ze de co-assistent op zo'n belangrijk punt goed kunnen beoordelen en feedback kunnen geven.

Voor de beoordeling van vaardigheden op het gebied van het lichamelijk onderzoek zijn er stationsexamens in PKO-2 en het centrale co-assistentschap. Dit examen bestaat in PKO-2 uit stations van gemiddeld zes minuten. In het centraal co-assistentschap 1 is er vooralsnog één station van twintig minuten waarin de coassistent een groot deel van het algemeen lichamelijk onderzoek bij een proefpersoon uitvoert. De studenten worden in dit station geobserveerd door de tutor van de betreffende groep. In het centraal co-assistentschap 2 is er een carrousel met zes onderdelen op het gebied van neurologie, psychiatrie en kindergeneeskunde. Drie van de onderdelen betreffen lichamelijk onderzoek bij echte patiënten of proefpersonen. Twee stations zijn schriftelijke opdrachten. De onderdelen duren acht minuten en vijf worden geobserveerd.

De cognitieve vaardigheden, weerspiegeld in het hanteren van klinische gegevens, worden in PKO-2 getoetst in de vorm van schriftelijke opdrachten. Daarnaast verzorgen de co-assistenten, voor de tutor en de overige acht leden van de tutorgroep van het centraal co-assistentschap 1 of 2 , een presentatie van een uur van de ziektegeschiedenis van een patiënt die ze gezien hebben. Dit wordt gedaan volgens de systematiek van de klinische probleemanalyse zoals die aan de faculteit in Nijmegen wordt onderwezen en toegepast. De tutorgroep als geheel dient daarnaast ook nog een klinisch-pathologische conferentie van anderhalf uur te verzorgen van een van hun patiënten. De patiëntendemonstraties worden door de docenten zeer gewaardeerd als middel om de co-assistenten op hun prestaties te beoordelen. Door het toegepaste karakter, ze behandelen immers klinische problematiek, wordt dit onderdeel ook als zeer leerzaam beschouwd.

Het grote verschil met voorheen is dat er op deze wijze een systematische beoordeling plaatsvindt op de kernpunten van het functioneren, het professioneel handelen, van een aanstaand arts.

\section{Onderwijsevaluatie}

De vragen die bij de schriftelijke evaluaties worden gesteld hebben betrekking op alle programmaonderdelen van de beschreven blokken en co-assistentschappen. Enkele belangrijke elementen van de evaluaties staan in tabel 1 en 2. De eerste evaluaties tonen een geschakeerd beeld. PKO-2 wordt duidelijk positiever beoordeeld dan het centraal co-assistentschap 1 .

Het blok PKO-2 wordt zowel naar vorm als naar inhoud hoog gewaardeerd. Het onderwijs wordt als zeer relevant beschouwd voor de opleiding terwijl ook het enthousiasme voor de opleiding duidelijk toeneemt tijdens PKO-2 (tabel 1). Het eindcijfer van 7.5 voor het blok als geheel is in vergelijking met de waardering van de blokken van het curriculum erg hoog te noemen. De inzet van de tutoren wordt ook hoog gewaardeerd. De mening van de studenten over het vernieuwde co-assistentschap interne geneeskunde is positief. De verschillende onderwerpen die in de evaluatie aan de orde komen, krijgen hoge waarderingen. Zowel de begeleiding als de beoordeling scoren met respectievelijk 3.3 en 3.6 duidelijk voldoende. Ook de organisatie en de leerzaamheid van het coassistentschap worden door de studenten sterk positief gewaardeerd. 
Bij de evaluatie van de centrale co-assistentschappen valt een aantal lage waarderingen op, met name bij het centraal co-assistentschap 1 (tabel 2). De relevantie van het blok voor de opleiding en het toenemen van het enthousiasme verwerven een zeer lage score van respectievelijk 2.3 en 2.4. Ook de onderdelen reflectie op de voorafgaande en voorbereiding op de komende co-assistentschappen krijgen van de studenten een laag cijfer. De werksfeer is in beide co-assistentschappen goed, maar de leerzaamheid in het centraal co-assistentschap 1 wordt als zeer matig beoordeeld. Ook de tutoren worden in het centraal co-assistentschap 1 iets minder gunstig beoordeeld dan in PKO-2, namelijk gemiddeld met 3.8, terwijl de waardering in het centraal co-assistentschap 2 weer toeneemt tot 4.2 .

\section{Bespreking}

De veranderingen in de vernieuwde klinische fase van de geneeskundeopleiding worden over het algemeen positief gewaardeerd zowel door studenten als docenten. Het blok PKO-2 met name wordt door beide groeperingen sterk posi-

Tabel 1. Gemiddelde waardering (Gem.) op een vijfpuntsschaal met standaarddeviatie (SD) en als cijfer (laatste vragen) uit de evaluaties door de eerste zes groepen van achttien studenten in 2000 van het PKO2 en het co-assistentschap interne geneeskunde.

\begin{tabular}{lc}
\hline $\begin{array}{l}\text { Vragen uit de evaluatie } \\
\text { (vrijwel dezelfde als op het evaluatieformulier) }\end{array}$ & $\begin{array}{c}\text { Studentoordeel } \\
\text { Gem. (SD) }\end{array}$ \\
\hline
\end{tabular}

\section{Evaluatie Praktisch Klinisch Onderwijs-2}

Over de rol van de tutor ben ik tevreden: $1=$ zeer oneens; $5=$ zeer eens

Ik vond de inhoud van het blok relevant voor de opleiding:

$\begin{array}{ll}4.4 & (0.6) \\ 4.8 & (0.5) \\ 4.2 & (0.3) \\ 4.1 & (0.4) \\ 3.9 & (0.3)\end{array}$

Mijn enthousiasme voor de opleiding is tijdens dit blok toegenomen:

De vorm van het onderwijs bij de verschillende onderdelen vond ik goed

Van mij krijgt dit blok als geheel als cijfer (1-10)

\section{Evaluatie Co-assistentschap interne geneeskunde}

Voorbereiding op het co-assistentschap

$1=$ zeer slecht; 5=zeer goed

Stageboek

Persoonsgebonden begeleiding

Kwaliteit patiëntgebonden leersituaties

Kwaliteit co-schapbeoordeling

Ik had een duidelijk takenpakket $1=$ volledig oneens; $5=$ volledig eens Het verblijf op de poli was leerzaam 
Tabel 2. Gemiddelde waardering (Gem.) met standaarddeviatie (SD) op een vijfpuntsschaal ( $1=$ zeer oneens; $5=$ zeer eens) en als cijfer (laatste vraag) uit de evaluaties door de eerste zes groepen van achttien studenten in 2000 van de centrale co-assistentschappen (CC-1 en CC-2).

\begin{tabular}{|c|c|c|c|c|}
\hline \multirow[t]{2}{*}{$\begin{array}{l}\text { Vragen uit de evaluatie } \\
\text { (vrijwel dezelfde als op het evaluatieformulier) }\end{array}$} & \multicolumn{4}{|c|}{$\begin{array}{l}\text { Studentoordeel } \\
\text { Gem. (SD) }\end{array}$} \\
\hline & \multicolumn{2}{|c|}{$\mathrm{CC}-1$} & \multicolumn{2}{|c|}{$\mathrm{CC}-2$} \\
\hline \multicolumn{5}{|l|}{ Centraal co-assistentschap } \\
\hline & \multicolumn{4}{|c|}{$1=$ zeer oneens; $5=$ zeer eens } \\
\hline Over de rol van de tutor ben ik tevreden. & 3.8 & $(0.9)$ & 4.2 & $(0.8)$ \\
\hline Ik vond de inhoud van het blok relevant voor de opleiding. & 2.3 & $(1.0)$ & 3.4 & $(0.9)$ \\
\hline Mijn enthousiasme voor de opleiding is tijdens dit blok toegenomen. & 2.4 & $(0.9)$ & 3.2 & $(0.8)$ \\
\hline \multicolumn{5}{|l|}{ De inhoud van de verschillende onderdelen vond ik goed: } \\
\hline Farmacotherapie & 4.2 & $(0.8)$ & 4.0 & $(0.7)$ \\
\hline Radiologie & 2.7 & $(1.0)$ & 3.6 & $(0.9)$ \\
\hline Klinisch pathologische conferentie & 3.6 & $(0.8)$ & 3.7 & (1.1) \\
\hline \multicolumn{5}{|l|}{$\begin{array}{l}\text { De vorm van het onderwijs bij de verschillende onderdelen werd } \\
\text { gelijkwaardig beoordeeld als de inhoud. }\end{array}$} \\
\hline De anamnese beoordeling is adequaat verricht. & 3.4 & $(1.2)$ & 3.8 & $(1.1)$ \\
\hline De reflectie op de voorafgaande co-assistentschappen vind ik geslaagd. & 3.0 & $(1.2)$ & 3.4 & $(0.8)$ \\
\hline De voorbereiding op volgende co-schappen vind ik geslaagd. & 1.9 & $(0.9)$ & 3.6 & $(1.0)$ \\
\hline Van mij krijgt dit blok als geheel als cijfer (1-10): & \multicolumn{4}{|c|}{ Cijfer 1-10 } \\
\hline Voor werksfeer & 7.2 & $(0.5)$ & 7.5 & $(0.8)$ \\
\hline Voor leerzaamheid & 4.4 & $(1.2)$ & 6.7 & $(1.0)$ \\
\hline
\end{tabular}

tief beoordeeld. Een verdere verbetering van het onderwijs in dit blok hopen wij te bereiken door het intensiveren van de tutorentrainingen. Het programma behoeft slechts aanpassing op enkele onderdelen.

De oordelen van de studenten over het co-assistentschap interne geneeskunde lopen tamelijk sterk uiteen voor de diverse klinieken. Er zal nog het een en ander aan de programma's moeten worden gesleuteld. Inhoudelijk is het programma redelijk op orde, maar de uitvoering laat soms nog te wensen over.

De ervaringen van de docenten met de nieuw ingevoerde onderdelen zijn positief. De patiëntendemonstraties en de beoordeling van de opgenomen anamnesegesprekken in het centraal co-assistentschap 1 en 2 worden gezien als een zeer nuttige en waardevolle uitbreiding binnen het kli- nisch onderwijs. Bij de laatste met name ook om de mogelijkheid de studenten feedback te geven naar aanleiding van een praktijksituatie. Patiëntendemonstraties vinden van oudsher plaats in het klinisch onderwijs, ook door co-assistenten. Maar binnen de centrale co-assistentschappen krijgen de co-assistenten de volledige aandacht. Zij hebben ruim de tijd om de besprekingen voor te bereiden. Ook voor de besprekingen zelf is ruim voldoende tijd gepland, zowel voor de co-assistenten als voor de docenten-tutoren. Ook de klinisch pathologische conferenties in de centrale co-assistentschappen 1 en 2 , die volledig door de studenten worden voorbereid en gepresenteerd, worden door de docenten en de studenten hoog gewaardeerd.

Een belangrijk leerdoel, samenhangend met de patiëntenbesprekingen, is verdie- 
ping van de in de voorafgaande co-assistentschappen opgedane kennis en ervaringen. Dit wordt beschouwd als een van de twee hoofddoelstellingen van de centrale co-assistentschappen, te weten reflectie op de voorafgaande en voorbereiding op de komende co-assistentschappen. Verdieping is een onderdeel van de volwasseneneducatie die de co-assistentschappen in feite zijn. Door ervaring gestuurd leergedrag is daarvan een belangrijk facet. ${ }^{8}$ Overigens wordt veel leren mede bepaald door ervaringen en is dit niet beperkt tot volwassenen. ${ }^{9}$

De patiëntendemonstraties en de voorbereiding daarvan zijn op zich reeds een vorm van verdieping. Daarnaast is in het programma een ruime hoeveelheid zelfstudietijd opgenomen voor de verdere uitwerking van thematiek uit de patiëntenbesprekingen of de co-assistentschappen met behulp van leerboeken, recente literatuur, bronnen op internet en overleg met experts van de betreffende disciplines. De ervaringen van de docenten tot nu toe hebben uitgewezen dat deze opzet niet voldoende is geslaagd. De thematiek uit de patiëntenbesprekingen wordt door de studenten te weinig uitgewerkt. Ook uit de evaluaties blijkt dat de studenten de reflectie matig waarderen. Als de tutoren individuele opdrachten aan de co-assistenten verstrekken, worden deze nauwelijks uitgewerkt. Bij de werkgroepbesprekingen van de ondersteunende disciplines blijkt telkens weer dat studenten te weinig stof ter bespreking en uitwerking aanbieden. De uitgewerkte thematiek van de patiëntenbespreking was speciaal hiervoor bedoeld. Zelfs was de opzet zo gekozen dat de studenten de door hen uitgewerkte probleemstellingen in de vorm van een kort referaat zouden kunnen presenteren. Deskundig commentaar van de docenten van de betreffende discipline zou dan verwerkt kunnen worden in de aansluitende bespreking van het onderwerp. Deze vorm was gekozen om de studenten de gelegenheid te geven de opdrachten op hun eigen wijze, gestuurd door hun eigen belangstelling, in te vullen.

Het ontbreken van voldoende inbreng van de studenten noodzaakt de docenten echter tijdens de werkgroepbijeenkomsten een soort responsiecolleges te verzorgen. De docenten zijn daarop vaak niet voorbereid, zodat de besprekingen onvoldoende rendement opleveren en zeker niet beantwoorden aan de oorspronkelijke doelstellingen. Deze ervaringen hebben een aantal docenten ertoe gebracht de studenten uitgewerkte opdrachten van tevoren te laten inleveren. Dit is enerzijds bedoeld om de studenten aan te sporen de opdrachten uit te werken en anderzijds als voorbereiding voor de docent op de werkgroepbesprekingen. Dit heeft geleid tot irritatie bij de studenten, die dit een schoolse manier van optreden vinden. De studenten zijn ook van mening dat ze al het werk voor niks doen als ze voor de ingeleverde opdrachten geen beoordeling of cijfer krijgen. In hun visie is er geen waardering voor hun werk, temeer omdat niet alle opdrachten worden behandeld. Deze onvrede komt ook duidelijk tot uiting in de op sommige punten lage appreciatie van de studenten voor het centraal co-assistentschap 1 .

Dit zijn op het eerste gezicht teleurstellende ervaringen. Waar wij stilzwijgend van uit zijn gegaan is dat de studenten de verdieping van hun ervaringen in de coassistentschappen spontaan op zich zouden nemen. Daarom werd in het programma veel ruimte voor zelfstudie gelaten en zijn de opdrachten over het algemeen globaal geformuleerd. Dat de studenten niet in de verwachte mate zelf vragen genereren, die uitgewerkt kunnen worden om zo verdieping van de opgedane ervaringen te bewerkstelligen, heeft 
een aantal mogelijke oorzaken. Blijkens de reacties van de studenten is de een of andere vorm van waardering voor het uitwerken van de opdrachten nodig. De voldoening voor zichzelf om verdieping van kennis te verwerven speelt een te kleine rol. Ook toetsing zou kunnen aanzetten tot meer verdieping. Hiermee geven de studenten ook zelf aan dat studiegedrag in belangrijke mate wordt bepaald door de toetsing. ${ }^{10}$ Uit onderzoek is daarnaast gebleken dat leren via reflectie een vaardigheid is die geleerd moet worden en dat diegenen die dit beginnen te beheersen een grotere medische competentie aan de dag leggen. ${ }^{11}$ Dat de evaluaties van het centraal co-assistentschap 2 een iets toegenomen waardering voor de reflectie tonen, zou een bevestiging kunnen vormen van de opvatting dat ook reflectie geleerd moet worden. Ook voor de voorbereiding op de komende co-assistentschappen bestaat in het centraal co-assistentschap 2 meer waardering. Dit laatste zou veroorzaakt kunnen worden door het zeer praktische karakter van de voorbereidingen in het centraal co-assistentschap 2, dat de studenten meer aanspreekt.

Verwondering en reflectie zijn dus doelstellingen die apart in het studiepakket zouden moeten worden opgenomen. In het licht van de continue scholing is het goed dat wij daarvan doordrongen raken.

\section{Literatuur}

1. Holdrinet RSG, Oeseburg B, Bulte JA, Leunissen RRM. Designing basic medical education in Nijmegen. In: Scherpbier AJJA, Vleuten CPM van der, Rethans J-J, Steeg AFW van der, redactie. Advances in medical education. DordrechtBoston-London: Kluwer Academic Publishers; 1997. p. 762-4.
2. Holdrinet RSG, Oeseburg B, Bulte JA, Leunissen RRM, redactie. Kerndoelstellingen tot het doctoraal geneeskunde. Nijmegen: Uitgave Faculteit der Medische Wetenschappen, Katholieke Universiteit Nijmegen; 1995.

3. Vernieuwing co-assistentschappen: klinische fase van het nieuwe Nijmeegse curriculum geneeskunde. Zevende rapportage Bestuurscommissie Herziening Curricula. Nijmegen: Uitgave Faculteit der Medische Wetenschappen, Katholieke Universiteit Nijmegen; November 1997.

4. Postma CT, eindredactie. Blokboek Praktisch Klinisch Onderwijs 2. Nijmegen: Uitgave Faculteit der Medische Wetenschappen, Katholieke Universiteit Nijmegen; september 2000.

5. Stageboek co-assistentschap interne geneeskunde. Nijmegen: Uitgave Faculteit der Medische Wetenschappen, Katholieke Universiteit Nijmegen; december 2000.

6. Postma CT, Metz JCM. Het ALCO-schap in Nijmegen. Bulletin Medisch Onderwijs 1989; 8:68-71.

7. Scott CS, Barrows HS, Brock DM, Hunt DD. Clinical behavior and skills that faculty from 12 institutions judged were essential for medical students to acquire. Acad Med 1991;66:106-11.

8. Bolhuis S. In Leren en veranderen bij volwassenen: een nieuwe benadering. Bussum: Dick Coutinho; 1995. p. 152-185.

9. Norman GR. The adult learner: a mythical species. Acad Med 1999;74:886-9.

10. Scherpbier AJJA. De Maastrichtse onderwijs benadering [inaugurele rede]. Maastricht: Universitaire Pers Maastricht; 2000.

11. Sobral DT. An appraisal of medical students' reflection in learning. Med Educ 2000;34:182-7.

De auteurs:

Dr. C.T. Postma, internist.

Prof. dr. W.J.H.M. van den Bosch, huisarts.

Dr. R. Laan, reumatoloog.

Allen zijn werkzaam bij het UMC St Radboud, Nijmegen

Correspondentieadres:

Dr. C.T. Postma, Afdeling algemeen interne geneeskunde 541, UMC St Radboud, Postbus 9101, 6500 HB Nijmegen, tel: 024-3618819, fax:024-3541734, C.Postma@aig.azn.nl. 


\section{Summary}

The reconstruction of the medical curriculum of the University Medical Center Nijmegen has progressed to the clinical clerkships. A mixture of theoretical and clinical hospital-based training has been accomplished. Clinical skills are systematically trained at the clinical training center, preceding ward-based training. The first training period in the hospital is the highly structured introductory clerkship, with emphasis on personal supervision of students. There are also small group sessions in the clinical training center. During the internal medicine clerkship the students receive a thorough training in patient management. The central clerkships, in between the clinical clerkships, are intended for reflection on the preceding clinical experiences and preparation for the following clerkships. Self-directed learning is an important feature of these central clerkships.

The mix of clinical and classroom-like activities, with patient care as the primary focus, offers opportunities for developing clinical experience and deepening of relevant knowledge. (Postma CT, Bosch WJHM van den, Laan R. The reconstruction of clinical clerkship in Nijmegen: early experiences. Dutch Journal of Medical Education 2001;20(5): 219-229.) 